\title{
O sentido da memória em "Elegia", de Cecília Meireles
}

\author{
Mariana Carlos Maria Neto
}

RESUMO: Neste artigo analisaremos o poema “Elegia”, de Cecília Meireles, tendo por finalidade compreender de que forma a memória auxilia o sujeito poético a libertar-se do luto e a refazer um sentido para sua percepção de mundo, que, depois da perda do ser amado, se encontrava fraturada.

PALAVRAS-CHAVE: Cecília Meireles; poesia; memória; afeto; morte.

ABSTRACT: This article analyses the poema "Elegia", by Cecilia Meireles, aiming to understand how memory helps the poetic persona free herself from mouring and reconstruct the meaning of her perception of the world, wich was broken after the loss of the loved one.

KEYWORDS: Cecilia Meireles; poetry; memory; affection, death. 
Com pouca dificuldade identificam-se o assunto e o tom de "Elegia", último poema de Mar absoluto e outros poemas (1945), de Cecília Meireles. Trata-se de uma composição produzida em razão da morte de Jacinta Benevides, avó de Cecília, que a criou depois da morte dos pais. "Elegia" pertence ao universo da confissão íntima: nele, o sujeito traça uma trajetória de confronto com o luto e de sucessivo alívio da dor, por meio da memória e do esforço em significar o vivido no presente. A poeta, apesar da profunda tristeza, constrói nesse longo poema uma homenagem ao amor cotidiano que está no silêncio "obrigatório e secreto" de nossas vidas.

Entendemos que toda a terceira ${ }^{1}$ parte de Mar absoluto e outros poemas, composta por "Elegia", ${ }^{2}$ deva ser encarada como um único longo poema, uma vez que nele há, além de unidade temática, uma espécie de progressão do assunto no tempo. O poema fora escrito entre os anos de 1933 e 1937, e, durante sua leitura, sentimos a mudança das estações do ano e da relação do sujeito com o luto. O contínuo e circular movimento da natureza revela aos poucos a imobilidade da poeta, que se vê prostrada diante de uma vida que se renova "inutilmente", já que o ser amado é perdido.

O leitor da poesia ceciliana deve estar certo de que a morte dá tom a toda reflexão da poeta sobre o instante. Esse pasmo é tão agudo para Cecília Meireles, que já era tema de suas elucubrações na infância:

Mas OLHINHOS DE GATO sentiu como se lhe puxassem o coração para fora do peito. Uma certeza súbita prendeu-a num círculo de sombra. Dentinho de arroz iria também. Iria numa noite dessas, quando ela estivesse dormindo, talvez. Tudo vai... tudo vai. Aperta-se com o dedo a água na pedra, e ela está fugindo, fugindo e continuando seu rumo... Consegue-se prender mansamente na mão um pássaro macio, e ele desliza para seu voo, e só se sente a leveza que deixam, quando já não estão... ${ }^{3}$

Essa "súbita certeza" é escancarada, em 1931, com a morte de Jacinta Benevides, a avó que lhe serviu de família e de quem era tão próxima. Enredada, a composição de "Elegia"

1. Mar absoluto e outros poemas é dividido em três partes, a primeira delas denominada "Mar Absoluto"; a segunda, "Os dias felizes"; e a terceira, "Elegia", composta por oito poemas numerados de " 1 " a " 8 ".

2. Por conta da extensão reduzida deste artigo, só transcreveremos por completo o poema “ 3 ”, uma vez que nele a relação entre memória, luto e amor é bastante expressiva.

3. MeIreles, Cecília. Olhinhos de gato. São Paulo: Editora Moderna, 1981, p. 10. 
acaba por lhe servir de alívio possível diante da perda, e a memória, a única matéria para a construção do poema. Por isso, apesar do intervalo de tempo entre a morte da avó e a composição do poema (cerca de dois anos), a intuição do leitor deve apostar que este é um poema de luto. Dada sua força afetiva, a perda não será de pronto aceita ou encarada como parte natural do ciclo da vida; nos poemas " 1 ", " 2 ", “3" e " 4 ", o sujeito colocará a morte à prova da realidade, buscando no mundo qualquer vestígio do ser amado. $\mathrm{O}$ fracasso dessa empreitada exige que a poeta busque as lembranças da vida que ambas dividiram e a materialidade do corpo morto e do cemitério. $\mathrm{O}$ confronto com a perda, ao final do poema, não abrandará a tristeza do sujeito; contudo, irá liberar a imaginação, que, nas quatro partes iniciais, está limitada pelo luto. Tal liberação proporciona a despedida final entre avó e neta, e põe fim ao fôlego que animara as oito partes do poema.

3

Minha tristeza é não poder mostrar-te as nuvens brancas,

e as flores novas, como aroma em brasa,

com suas coroas crepitantes de abelhas.

Teus olhos sorririam,

agradecendo a Deus o céu e a terra:

eu sentiria teu coração feliz

como um campo onde choveu.

Minha tristeza é não poder acompanhar contigo

o desenho das pombas voantes,

o destino dos trens pelas montanhas,

e o brilho tênue de cada estrela

brotando à margem do crepúsculo.

Tomarias o luar nas tuas mãos,

fortes e simples como as pedras,

e dirias apenas: "Como vem tão clarinho!". 
E nesse luar das tuas mãos se banharia a minha vida,

sem perturbar sua claridade,

mas também sem diminuir a minha tristeza.

No poema " 3 ", a revolta diante da perda ganha o aspecto da tristeza, do não poder estar contigo, e a natureza vai ratificar a saudade e mostrar o caráter do que fora perdido. Veremos aqui que a poeta se dedicará a relembrar e reconstruir os modos da avó em relação à natureza, mais especificamente, a uma natureza domesticada, comum aos jardins e aos quintais. Daquele lugar do qual podemos ver, sem medo, as frutas amadurecendo para serem comidas, as flores desabrochando e toda sorte de delicadezas naturais.

Como se trata de um poema que nasce amparado na memória, ele configura o encontro de duas temporalidades: a do passado, na presença da avó, quando o eu lírico apontava o mundo, e a do presente, em que a poeta, estática, observa o fim do dia. Além desse encontro de tempos, há ainda o tempo de duração do próprio poema, que se inicia durante a tarde com suas nuvens brancas, passa pelos pássaros procurando repouso e pelas primeiras estrelas nascendo no poente, para terminar com o luar. O clima crepuscular chama atenção para uma delicada tristeza que vai se ampliando pela saudade. Apesar da aproximação entre o crepúsculo e a tristeza da poeta, a natureza não se afeta com a vida íntima de Cecília, mas, de um modo bastante duro, se oferece tal qual era durante a vida da avó, ressaltando ainda mais a falta e também uma separação entre o que o sujeito sente e a vida exterior.

A poeta lança mão do futuro do pretérito ("sorririam", "sentiria", "banharia"), para dar vazão à saudade, reconstruindo o que a vida havia sido na presença do ser amado e enumerando o que fora para sempre perdido. E por mais que esteja cheio de seres e cenários, esse poema é marcado pelo vazio, retomado a cada repetição do sintagma "minha tristeza é não poder". Tal mote submete todo o visto, enumerado na primeira e na terceira estrofes do poema " 3 ", a uma acentuada falta de significado, uma vez que a memória não supre a falta. De toda forma, a retomada dos hábitos cotidianos de avó e neta vai construindo um retrato íntimo dessas duas mulheres e as particularidades do afeto que tinham uma pela outra.

Na narrativa de memórias Olhinhos de gato, a avó, Boquinha de Doce, insurge como uma figura conhecedora de uma natureza cíclica e eterna e guardadora das narrativas que atribuem sentido à vida, sempre compreendendo os seres e as plantas, profundamente.

Conforme a lua, deitam-se galinhas, e num dia previsto e infalível, nascem pintos que Boquinha de Doce ajuda a retirar das cascas, formas úmidas e moles, enroladas em si 
mesmas, e que ela facilmente desenrola e anima, falando num sorriso: "Vamos nascer que já é hora!”. E eles dizem que sim, com um claro biquinho novo, cor de milho tenro [...].

Ah! Boquinha de Doce iria, então, ficar velha também, assim? Não. Boquinha de Doce conta-lhe muitas estórias prodigiosas $[\ldots] . .^{5}$

Então, a menina sentia brisa e sol por dentro de si. Saltava pelas pedras, abraçava-se às árvores. Tudo renascera! Tudo renascia! Boquinha de Doce, de mãos postas, parava no alto da sacada, olhando. A menina considerava-a de longe, com pensamentos indeterminados, mas que exprimiam esta emoção: "Ela é imortal!”.

A vida, quando tocada pela avó, se ordenava de uma forma idílica, e tudo era chamado a despertar. A habilidade com o mundo natural parece também ligada à capacidade de contar "estórias prodigiosas" que inserem a avó numa espécie de núcleo de verdade, garantindo-lhe eternidade. Pelos olhos da neta, Jacinta tinha tamanho manejo da vida que a entendia por dentro, fazendo parte de uma espécie de núcleo de uma grande narrativa. Em razão disso, na falta da avó, a poeta busca os lugares nos quais Jacinta sempre esteve inserida, de forma tão totalizante, e surpreendentemente não encontra no ambiente o sentido que o olhar da avó atribuía à vida.

Como esse é um poema dialógico, por mais que seja solitário, as supostas respostas de Jacinta aos acenos da neta configuram aquilo que falta à cena depois da morte da avó. Ao que nos parece, o "mostrar" da poeta só vê sentido no sorriso que a avó abriria, "agradecendo a Deus o céu e a terra”. É como se a poeta não fosse capaz de sozinha construir o sentido que vai do céu a terra; dessa maneira, o transbordamento do sorriso da avó traria também para sua vida a felicidade e a calma de "um campo onde choveu". Estruturalmente, percebemos que o poema se divide em estrofes que descrevem uma ação impedida, como na primeira e na terceira ("é não poder mostrar-te"; "é não poder acompanhar contigo"), e naquelas que relembram, a segunda, a quarta e a quinta, as respostas para essa falta (com verbos no futuro do pretérito). Existe nessa alternância um interessante jogo entre mobilidade e imobilidade que vai,

\footnotetext{
4. Meireles, Cecília. Op. cit., p. 22.

5. Idem, p. 16 .

6. Idem, p. 30 .
} 
no decorrer do poema, retratando a forma específica como cada uma delas interage com o movimento da vida.

Logo na primeira estrofe, notamos o movimento do olhar da poeta do alto ("as nuvens brancas") ao baixo ("as flores novas"). Há aqui um encantamento quanto ao que se vê, que incide sobre o substrato sonoro do poema pela repetição da consoante plosiva e a vogal aberta ("brancas", "brasas", "abelhas"), que forçam o leitor à pronúncia mais lenta e aberta, dando uma impressão de espanto diante da beleza da natureza. Entretanto, apesar da beleza, o olhar passa pelas imagens sem se fixar em nenhuma delas, de tal maneira que cada imagem se encerra em um único verso. Essa postura da percepção pode estar amparada pela natureza daquilo que é visto; tanto nessa primeira estrofe quanto na terceira, todos os objetos de seleção da poeta indicam mobilidade: as nuvens, as abelhas sobre as flores, as pombas se recolhendo para o sono, os trens que cortam as montanhas e as estrelas brotando no crepúsculo. Talvez inspirada pelo fluir que a natureza sugere, a poeta opte por não reter as imagens descritas. Mas, devido à própria seleção de objetos, esse procedimento também descreve uma espécie de imaginação voltada ao movimento, algo semelhante ao que Bachelard entenderá sobre o imaginário do ar.

Nesse estudo dos tipos de imaginação, cabem ao ar as representações da mobilidade, de tal forma que uma representação ideal desse tipo de imaginário necessitaria de um fluxo contínuo de imagens, dando a sensação de uma espécie de "imaginação sem imagens". 7 Essa forma de mobilidade é comum à poesia de Cecília Meireles e deixa-nos uma sensação de suave elevação do espírito e de aparente uniformidade. Tão definitiva é essa postura poética, que muitas vezes a mobilidade é mais expressiva do que as próprias imagens que vão sendo retratadas. Esse ritmo impõe a fluidez à concretude do cotidiano, restando ao leitor a tão falada impressão de uma poesia apartada da vida concreta e distante do mundo. Ao colocar-se no fluxo contínuo de uma imaginação dinâmica, a poeta não só se aparta do cotidiano como também não se fixa em estados de ânimo, como ela bem ensinou em "Motivo": "Não sou alegre nem sou triste:/ sou poeta.// Irmão das coisas fugidias,/ não sinto gozo nem tormento./ Atravesso noite e dia/ no vento".

No poema “ 3 ", vemos que essa mobilidade está comprometida pelo luto, que não permite que a imaginação alce seu voo em direção à conformação de um sentido. Por

7. BACHelard, Gaston. O ar e os sonhos. Tradução de Antonio de Pádua Danesi. São Paulo: Martins Fontes, 1990, p. 2. 
conta disso, na primeira e na terceira estrofes, as imagens de fluidez estão atravessadas pelo motivo da tristeza, de tal maneira que cada verso mobiliza, através da imagem que descreve, mais uma faceta da falta e da imobilidade, afinal a tristeza restringe a ação e a imaginação da poeta. Os versos dessas estrofes são predominantemente nominais, tendo como núcleo da ação o verbo "ser". A escolha pelos infinitivos e gerúndios ("não poder mostrar-te"; "brotando") inclina, novamente, nossa sensibilidade mais à imagem do que à ação, que neste poema está severamente comprometida. Essas estrofes encerram em si uma tensão, sempre aliviada na estrofe seguinte, quando a avó, renascida pela lembrança da poeta, reorganiza a falta encenada.

Nessas estrofes, em que a memória resgata a presença da avó, teremos um maior uso verbal ("sorririam", "sentiria", "choveu”, “Tomarias", "dirias", "se banharia"). A dinamicidade da vida que se oferecia era recebida por Jacinta com alegria; a avó de Cecília, ao agradecer "a Deus o céu e a terra", oferece uma unidade pacificadora para o fluxo constante de imagens que se reorganizam em seu coração, que é como "um campo onde choveu". O silêncio e a tranquilidade de um campo onde choveu destoam das imagens móveis construídas na primeira estrofe.

Na segunda estrofe, a avó tem pouquíssimo movimento, mesmo seu sorriso é demonstrado pelo olhar (“Teus olhos sorririam"). Centrada e quieta, ela se opõe à atitude da neta que apontava e mostrava a vida exterior. Mas, apesar da tranquilidade, são suas reações que atribuem significado ao visto; a partir delas, o lépido movimento do apontar ganhará densidade de sentido. Essa dialogia constrói uma dicotomia no poema " 3 ", uma vez que o sentido do visto só é alcançado nas estrofes em que a memória resgata as ações da avó diante do mundo. Formula-se, então, uma espécie de esquema em que a ausência da avó implica um desligamento de sentido entre a vida íntima e aquela percebida pelos sentidos. Jacinta, assim como fora nas narrativas da infância, parece filtrar o mundo por um viés ordenador, que era capaz de desacelerar ou mesmo frear o movimento incessante da vida e indicar novas possibilidades para a sensibilidade.

Eu tenho conhecido muita gente: do mundo inteiro, de todas as idades, religiões, níveis de cultura e educação. Sempre penso que minha Avó era uma raridade. Se ela tivesse vivido noutro ambiente, com outros recursos ao seu alcance, quem sabe eu seria apenas a sombra do que ela deixou de ser? [...] Quando minha vida fica muito triste, sonho logo com minha Avó. Sonho com sua casa, volto a encontrá-la, [...]. E depois acordo. Tenho muita pena de não ter feito por ela muitas coisas que na verdade não pude fazer. Sempre 
me acho mesquinha, insuficiente, débil. Mas também ela não precisava de mim para nada. Ela vivia num outro plano, que sempre pensei que Deus fosse seu amigo pessoal, parente nosso, cujo endereço ela conhecia e frequentava. ${ }^{8}$

O trecho da carta não pode ser lido fora do âmbito do afeto; por isso, ele mais revela o que ficou impresso na poeta do que descreve algo de preciso sobre a avó. E se o retrato não interessa tanto a um possível biógrafo, ele é muito significativo para quem deseja entender "Elegia". Nele vemos que Jacinta parecia dotada de um conhecimento sobre o destino da criação. É esperado, portanto, que seu coração não se mova com o fluir que o mundo oferece, mas que se fixe na certeza de um segredo que o tranquiliza.

A lembrança da avó, do "campo onde choveu", expande o olhar da poeta, anteriormente focado no diminuto ("flores", "abelhas") e no perecível ("nuvens"), e direciona o poema para a altura do horizonte. Apesar de não estar se movendo do alto ao baixo, como na primeira estrofe, o olhar da poeta retoma as imagens dinâmicas (o voo, o trem, o crepúsculo). A primeira delas é "o desenho das pombas voantes", seguida pelo "destino dos trens pelas montanhas"; ambas trazem a ideia da linha e de um sentido do mover-se. O movimento das pombas assim como o dos trens pelas montanhas obedece a algum sentido linear, do percurso que realizam e do destino a que obedecem. O percurso ("desenho") e o "destino" podem se entrelaçar através da ideia de sentido, seja material ou espiritual. Ao que nos parece, apesar de discreta, existe aqui uma inflexão, pois a lembrança da avó mobiliza a busca de um novo sentido, que parece tentar se construir pela ideia do percurso. E talvez aqui caiba retomar a bela epígrafe de Rilke ${ }^{9}$ que abre "Elegia", retirada da carta de 26 de dezembro de 1908, na qual o poeta tenta explicar a Kappus a importância da solidão. Para tanto, vale-se da influência secreta que nossos antepassados têm em nossa vida:

Em tudo o que o senhor tiver que viver e fazer, ela [a solidão] agirá como uma influência anônima, assim como o sangue de nossos antepassados se movimenta em nós, misturando-se ao nosso e formando com ele a única coisa única e irreparável que somos em cada curva de nossa vida. ${ }^{10}$

8. meireles, Cecília. Lição do poema, cartas de Cecília Meireles a Armando Côrtes-Rodrigues. Organização e notas de Celestino Sachiet. Ponta Delgada: Instituto Cultural Ponta Delgada, 1998, p. 71. 9. "Elegia" tem como epígrafe um trecho de Cartas a um jovem poeta, de Rilke.

10. RILKE, Rainer Maria. Cartas a um jovem poeta. Tradução de Paulo Rónai. 24 ed. São Paulo: Editora 
Acreditamos que a poeta procure por esse sentido quando apela para o movimento dos trens e das pombas, provavelmente buscando entender onde nela repousa essa "coisa única e irreparável", uma bússola que lhe dê o sentido que Jacinta ${ }^{11}$ por tantas vezes soube encontrar, nos numerosos lutos que experimentou. Ao final do poema "6", a poeta desenvolve o que aqui é só uma indicação, e descreve essa trajetória triste, coberta de perdas, vivenciada pela avó:

\author{
Mas puseram-te numa praia de onde os barcos saíam \\ para perderem-se. \\ Então, teus braços se abriram, \\ querendo levar-te mais longe: \\ porque eras a que salvava. \\ E ficaste com um pouco de asas. \\ Teus olhos, porém, mediram a flutuação do caminho. \\ Por isso, tua testa se vincou de alto a baixo, \\ e tuas pálpebras meigas \\ se cobriram de cinza.
}

De tanto ver os barcos "perderem-se", Jacinta acaba por abrir os braços querendo arremessar-se mais longe, mais ao alto, porque ela havia ficado "com um pouco de asas", mas seus sábios olhos conseguiram medir a incerteza do caminho e sua testa "se vincou de alto a baixo”. A pequena narração é bastante simbólica, mas não deixa de nos causar sugestões precisas que referenciam a história de vida de Jacinta em relação à perda dos netos, da filha, do genro e do marido. O que nos leva a pensar que o envelhecimento (a testa vincada) chegou para Jacinta como uma espécie de resistência, um não se entregar à morte, que a fez abrir mão das asas e fincar-se em terra firme, com o peso das cinzas sobre seus olhos. É essa firmeza que Cecília busca durante o poema “ 3 ”, primeiro através da natureza que ambas amavam e na qual Jacinta parecia tão intimamente inserida e, segundo, na memória, dada a impassibilidade da natureza diante da tristeza.

Globo, 1996, p. 75.

11. A avó tornou-se, junto de Cecília Meireles, sobrevivente de uma família que se desfez. O pai de Cecília falece em 1901, a mãe em 1904. Sem contar os irmãos, que faleceram antes de a poeta nascer. 
Como não reconhece em si a força que via na avó, sua imaginação dinâmica quebra com as imagens de linearidade, provavelmente por não alcançar o sentido que procurava, e salpica junto das estrelas que nascem depois do pôr do sol ("e o brilho tênue de cada estrela/ brotando à margem do crepúsculo"). O espalhamento da linha em pontos, novamente, só retornará para uma ideia de unidade através da lembrança da avó, nas estrofes finais:

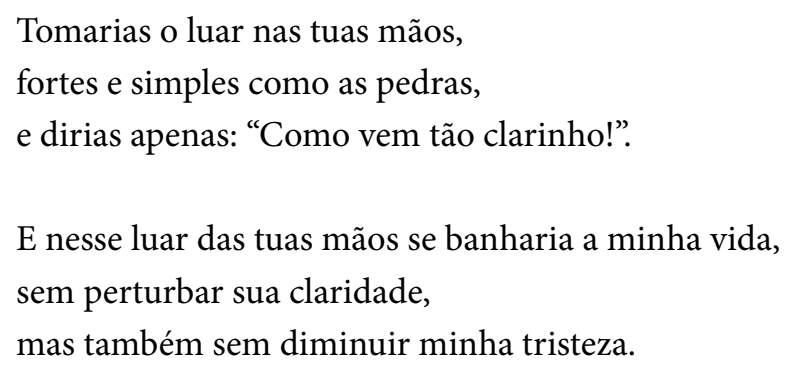

A avó é responsável por trazer o sentido que se perde, e como recolhesse a luminosidade esparsa das estrelas, cria uma unidade e a traz para perto da neta. Assim como fizera viver os pintinhos, Jacinta faz o parto da lua: "Como vem tão clarinho", e ilumina o final do poema " 3 ". O uso do diminutivo não só incide numa atitude afetuosa como também prolonga a fala da avó, o que se intensifica pelo uso do advérbio "tão", de tal maneira que o tempo da leitura sugere o movimento das mãos que vão buscar o luar. Por isso, no verso posterior, o luar já está assentado junto de Jacinta. Há no "luar das tuas mãos" um movimento de equalização de dois planos opostos (alto e baixo), uma vez que a lua não está refletida em suas mãos, e sim o luar é emitido por elas, pois a preposição "de" ("luar das tuas mãos") carrega consigo esse significado de pertencimento. Essa aproximação de céu e terra é marca definitiva das ações da avó no poema: primeiro através da totalidade de Deus (que agrega o céu e a terra), na quinta estrofe, depois por meio da imagem do "campo onde choveu", e, por fim, na descida da lua ao chão.

É complexa a cena construída nessa última estrofe. As mãos de Jacinta são como pedras ("fortes e simples") e trazem o luar em si, onde Cecília pode banhar sua vida. A escolha lexical ("luar", "banhar" e "pedras") sugere ao leitor uma espécie de lago, criado a partir da lua e suportado pelas mãos da avó. O quadro é de acolhimento, contudo de uma proteção que não satisfaz o sujeito, afinal a saudade persiste e a claridade da lua não é capaz de diminuir a tristeza. Toda a exuberância da imagem final, mais uma vez, não coincide com o estado de ânimo da poeta. 
O poema vinha se amparando na memória para recriar as cenas de convívio e as reações da avó diante da natureza, na estratégia de aliviar a dor. Assim podemos entendê-lo até a penúltima estrofe, já que, na última, a imaginação afasta a poeta dos elementos concretos (da tarde e do pôr do sol) e lhe possibilita criar essa espécie de lago, feito da lua e das mãos da avó. Contudo, a transfiguração do real, que costuma ser muito proveitosa na lírica ceciliana, não é capaz de apaziguar o luto, e a fantástica imagem final só faz iluminar a tristeza e a solidão magoada da poeta.

Mas, como dissemos, o poema "Elegia" deve ser encarado como um todo. Uma narração lírica da perda que culmina numa síntese entre o luto e o amor, forjada pela memória e pela imaginação. Por isso, no poema " 8 ", o sujeito poético, depois do longo lamento da morte, encontra-se menos impedido pelo luto e se vê capaz de reencontrar sua avó para uma despedida final.

Na sétima estrofe do poema final de "Elegia", a poeta retira sua avó do túmulo em que fora enterrada e pede que ela ouça "amplo e difuso rumor da cidade em que continuo". O pedido, apesar da referência à cidade, é voltado para o mundo que ambas amaram juntas e ao qual a poeta recorreu durante todas as partes de "Elegia":

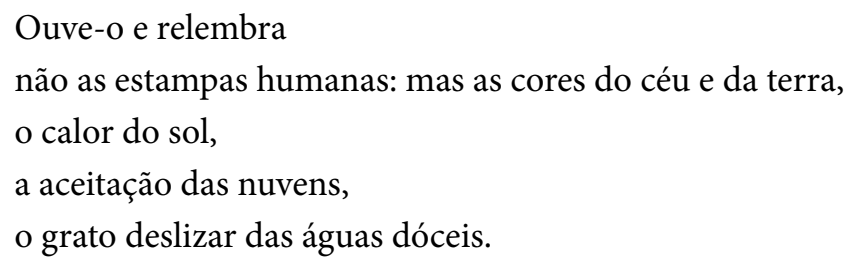

À avó, agora residente no “tempo unânime”, é apontado aquele mundo que já não mais a continha, mas que ela amara. A retomada dessa exterioridade funciona no poema como reafirmação de um compromisso ("Tudo o que amamos juntas./ Tudo em que me dispersarei como te dispersaste") reatado através da memória. Depois da aproximação da avó e de retomado o mundo que ambas amaram, a poeta passará a consolar a morta da distância que as separa; "Apenas, não podemos correr, agora,/ uma para a outra":

Não sofras, por não te poderes levantar do abismo em que te reclinas: não sofras, também, se um pouco de choro se debruça nos meus olhos, procurando-te. 
A tristeza do poema " 3 " estava em não poder estar contigo na fruição do mundo, como já comentamos. Aqui a poeta fará o exercício pelo lado da avó, acalmando-a das dores que lhe sobraram desde a separação. Os sofrimentos da avó estariam ligados ao campo semântico da morte e da imobilidade, como: "Não sofras, por não te poderes levantar" e "Não te importes que escute cair/ [...] teu crânio, tuas vértebras". Mesmo quando retomada pela memória, Jacinta não é uma figura de muita mobilidade, contudo seus poucos gestos são dotados de uma serenidade que reconhece um sentido da vida. A morte, em seu caso, transforma o pouco movimento em imobilidade e a noção de sentido em "abismo". A imagem do "abismo em que te reclinas" não é só belíssima como também é precisa para figurar o mistério e a inacessibilidade da morte. O sentido de unidade que Jacinta trazia à vida não desaparece com a morte, mas se fecha em si mesmo, compartilhando, em uma "linguagem inviolável", com a natureza, o segredo da vida.

A emotividade desse lamento final é seguida da última formulação de consolo do poema, "Não te importes. Não te importes...", e marca a liberação da imaginação para a transfiguração do real:

Na verdade, tu vens como eu te queria inventar:

e de braço dado desceremos por entre pedras e flores.

Posso levar-te ao colo, também,

Pois na verdade estás mais leve que uma criança.

- Tanta terra deixaste porém sobre o meu peito!

irás dizendo, sem queixa,

apenas como recordação.

E eu, como recordação, te direi:

- Pesaria tanto quanto o coração que tiveste,

o coração que herdei?

Ah, mas que palavras podem os vivos dizer aos mortos?

A liberação da imaginação para a construção de um sentido vai possibilitar o diálogo final, em que a poeta enterra novamente a avó e firma uma espécie de acordo. A fala de Jacinta reclama um direito à vida e uma resistência à morte ("Tanta terra deixaste porém sobre o meu peito!”). O apelo de Jacinta parece incoerente, afinal poderia indi- 
car um pedido pela manutenção do luto; contudo, ele configura o exato oposto. A fala da avó alerta sobre o poder da memória, que, diante da morte de um ser amado, faz viver não só o ente perdido como também aquele que sofre. Em razão disso, mesmo que ainda chorosa, a poeta sela um pacto de vida: a terra pelo coração ("Pesaria tanto quanto o coração que tiveste,/ o coração que herdei?"). Se o coração pode simbolizar o que somos no mais individual, a troca representa uma equalização entre a avó e a neta, que passam a viver juntas.

A morte da avó fora para o eu lírico um total despedaçamento, que, como vimos no poema " 3 ", impossibilitou o sujeito de restaurar qualquer unidade de sentido. $\mathrm{O}$ ato, portanto, de herdar o coração figura numa sobrevivência não só da memória da avó como também da própria poeta. Novamente, é da mais profunda falta que Cecília Meireles encontra meios de ressignificar sua trajetória diante dos fenômenos que lhe tomem a inteligência e o coração.

O exercício final do poema é o do reconhecimento do outro mesmo na falta: "Não tens fala, nem movimento nem corpo./ E eu te reconheço". Acreditamos que esse reconhecimento vem de dentro, o pacto de troca fez viver o coração de Jacinta, e sua ausência vive por meio da poeta. Contudo, a presença construída pela memória não é capaz de superar o oculto e a inacessibilidade da morte, uma vez que a poeta não sabe se é reconhecida pela avó: “Ah, mas a mim,/ quem sabe se me poderás reconhecer!". E o poema finda na certeza de um limite para a memória e para o afeto: o mistério que circunda a morte.

Se é possível vislumbrar uma síntese possível, entendemos que o vínculo reafirmado entre elas é consolidado pela experiência do mundo compartilhado. A exterioridade dos ambientes e dos modos é retomada pela memória e consolida um vínculo que sobrevive às "estampas humanas" e representa uma modalidade do eterno. De alguma forma, essa eternidade construída pelo estar com, não só em "Elegia" mas também em Mar absoluto e outros poemas, expressa-se como uma proteção contra a perenidade do humano, uma vez que a memória afetuosa é capaz de reconstruir o sentido perdido, e vislumbrar, nesse caso através do próprio poema, algum tipo de unidade e solidez.

Mariana Carlos Maria Neto é mestre em Literatura Brasileira pela Universidade de São Paulo. 